\title{
Quenching A-coefficients by photons in a short discharge tube
}

PPPL--2861

DE93 002630

\author{
H. Cao, D. DiCicco and S. Suckewer \\ Dept of Mechanical and Aerospace Engineering \\ and Plasma Physics Laboratory \\ Princeton University, Princeton, NJ 08544.
}

\begin{abstract}
New experimental results on quenching of A-coefficients by photons in a short discharge tube are presented. Experiments with the short discharge tube have eliminated questions related to the effects of absorption in a long laser tube, and have provided good confirmation of earlier results.

\section{Introduction}

Einstein $A$ and $B$ coefficients are treated as constant coefficients for atoms and ions. For isolated atoms and ions this is true, as was shown many years ago by Weisskopf and Wigner, 1 and the Fermi Golden Rule formula may be directly applied (see e.g., Ref. 2). However, for atomic systems which are not isolated but under the influence of electromagnetic field, which perturb them on a time scale $\tau$ much shorter than $\tau_{A}=A^{-1}$, the assumptions on which the Fermi Golden Rule formula is based might be violated.2 Hence, in such a case $A$ and $B$ values may not be the same as for isolated atomic systems. For example, in plasmas one would expect quenching of $A$ (as well as B) coefficients for transitions for which $\tau_{A} \gg \tau$, where $\tau$ in this case is determined by the frequency of inelastic collisions between electrons and atoms or ions.3.4 A similar effect could be expected also for atoms and ions under frequent "collisions"
\end{abstract}


with photons, e.g., in relatively high power density laser beams (quenching A-coefficients by photons ${ }^{5}$ ).

One of the major issues raised by Hans Griem6,7 concerning our paper on quenching A-coefficients by photons 5 was the question of power broadening of stronger lines and the related effect of the decrease of the absorption of these lines in a long discharge laser tube. Although some of our measurements and calculations indicated that this should not be the case, ${ }^{7}$ we believed direct experimental evidence would be the best indicator of the validity of this explanation. Our approach was to place a short diccharge tube, in which the absorption is egligible for all lines of interest, inside a laser cavity. This configuration eliminates the possible change of absorption for stronger lines. Another advantage of a short discharge tube placed inside the laser cavity is that one may change discharge conditions in the tube, leading to the change of levels population, without changing the power density in the resonator.

In this new experiment we also replaced our previous one-channel type detectors on spectrometers with multichannel detector. This allowed us to monitor simultaneously lines for which quenching of A-coefficients could occur and those for which quenching was not expected.

\section{Experimental Arrangement}

Figure 1 shows the experimental setup. A short discharge tube filled with argon gas was placed inside the cavity of an argon ion laser (COHERENT-Innova 200). The reason for placing the short tube inside the cavity was that the photon flux inside the cavity was much higher and more uniform than that obtainable outside the cavity. The effective length of the discharge tube was $4.5 \mathrm{~cm}$ and its inner diameter was $5 \mathrm{~mm}$. Discharges in the short tube were created in a pulsed fashion to avoid overheating. Rogowski coil connected to an oscilloscope was used to monitor the discharge current. The short tube was cut 
at Brewster angle on its ends in order to reduce losses inside the laser cavity introduced by this tube.

A high reflectivity mirror with a $4 \mathrm{~mm}$ hole in its center was placed inside the laser cavity and tilted at 45 degree to the laser beam path. While the laser beam, $2 \mathrm{~mm}$ in diameter, could pass through the hole of the mirror and oscillate inside the cavity, the spontaneous emission from the short discharge tube could be reflected by the mirror out of the cavity. The spontaneous emission from the short tube was focused onto the eritrance slit of the spectrometer by achromatic lens. A dichroic filter was used to block the scattered laser light. The argon ion laser was tuned for lasing at a particular lasing line or to nonlasing by rotating the prism and the end-mirror. In this way it was possible to control the photon density inside the cavity over a large range. The intra-cavity photon density was monitored by measuring the laser output power.

The spectrometer was a $0.5 \mathrm{~m}$ Ebert-Fastie type JarrellAsh monochromator with a 1200 groove $/ \mathrm{mm}$ holographic grating. In order to make the lines of interest well separated from their neighboring lines, the width of the entrance slit was set at $10 \mu \mathrm{m}$ and the spectrum was observed in second order. At the exit of the spectrometer a multichannel detector head (Princeton Instruments, Model IRY-700) was installed. The multichannel detector controller was used to control the gating system of the detector head and transmit the data (spectra) to an Apple Macintosh II.

The synchronization between discharges in the small tube and data acquisition system was accomplished by computer control of the experimental operation. The detector head was gated open for the time of the discharge and the first spectrum was recorded. After the discharge, the detector head was gated open again for the same amount of exposure time in order to record the background spectrum. The final spectrum was obtained by subtracting the background spectrum from the discharge spectrum.

Since the laser light had no effect on argon ions or atoms outside the beam path, it was crucial in this experiment 
to image on the entrance slit of the spectrometer only the part of argon gas, which was in the laser beam path. In order to satisfy this condition, the height of the entrance slit had to be carefully masked followed by fine alignment of the focusing lens.

Although the spontaneous emission from the long discharge tube was much stronger than that from the short tube, most of it was reflected by the back side of the $45^{\circ}$ mirror and traveled away from the spectrometer. A very small part of this radiation, which was reflected by the end-mirror and entered the spectrometer, was much weaker (by factor of 5-10) than that from the short tube. Because the discharge in long tube was running in continuous mode, its spontaneous emission spectrum played the same role as a background radiation and therefore canceled after substraction in the final spectrum. A number of spectra were taken under the same experimental conditions and were averaged in order to minimize the shot-toshot fluctuations.

Finally, the possibility of nonlinear response of the detector or optical components due to the laser beam power has been checked (similarly as in. Ref. 8) and excluded as a potential cause of error.

\section{Experimental Results}

As a first step in our experimental program we measured the intensity branching ratio of Ar II $399.2 \mathrm{~nm}$ and $442.6 \mathrm{~nm}$ lines in the laser discharge tube. Both transitions are from the common upper $4 p{ }^{4} D_{5 / 2}$ level down to $3 d{ }^{4} D_{3 / 2}$ and $4 s{ }^{4} P_{3 / 2}$ levels, respectively, with A-coefficients for unperturbed ions being about 50 times lower for the $399.2 \mathrm{~nm}$ line than for the $442.6 \mathrm{~nm}$ line. (Partial energy diagrams for these and other ArII transitions of interest for this work as well as discussion of A-coefficients for non-perturbed ArII ions were presented in earlier papers 5,8 ). These were practically the same type of measurements as those presented earlier 8 except that in this work the spectra were recorded with a multichannel detector 
instead of a single line intensity measurements with photomultiplier. Measurements were performed for a different laser beam power at wavelength $514.5 \mathrm{~nm}$. The results obtained were in excellent agreement with earlier results. ${ }^{8}$

In the next step we proceeded with our experiments with a short discharge tube. In Fig. 2a,b a typical set of spontaneous emission spectra from short discharge tubo with Ar-ion laser "on" and "off" ("lasing" and "nonlasing" conditions) is shown. The spectra for laser "on" were obtained with beam power $\sim 4.4 \mathrm{~W}$ for $514.5 \mathrm{~nm}$ lasing line. While the intensity of $442.6 \mathrm{~nm}$ line (Fig. 2a) remained almost the same during "lasing" and "nonlasing," the intensity of the $399.2 \mathrm{~nm}$ line (Fig. 2b) decreased $\sim 8 \%$ when the argon ion laser was lasing at $514.5 \mathrm{~nm}$ resulting in the decrease of the intensity branching ratio $R=I_{399.2} / I_{442.6}$. Another spontaneous emission line $(396.8 \mathrm{~nm})$ in Fig. 2b, also having the same upper level as $514.5 \mathrm{~nm}$ lasing line, decreased about $4 \%$ in its intensity under lasing conditions. This change agreed with our earlier hypothesis 5,8 that quenching is smaller for lines with larger Acoefficients. For all other neighboring lines with different upper levels from the $514.5 \mathrm{~nm}$ line we did not observe any intensity changes. This confirms that the observed changes were not due to statistical fluctuations. The intensity branching ratio of the $399.2 \mathrm{~nm}$ and $442.6 \mathrm{~nm}$ lines was also measured when the argon ion laser was lasing at another lasing line $(448.0 \mathrm{~nm}$, see Fig. 3). No change in this branching ratio was observed, which is in agreement with earlier measurements. 8

Figure 4 presents the branching ratio $R=I_{399.2} / I_{442.6}$ (normalized to 1 for non-lasing condition) versus intra-cavity laser power density at $514.5 \mathrm{~nm}$. As the photon flux increased, the branching. ratio decreased. The largest decrement observed in this experiment was $\sim 12 \%$. (Note: for power density $4 \mathrm{~kW} / \mathrm{cm}^{2}$ at wavelength $514.5 \mathrm{~nm}$ the $\tau \approx 4 \times 10^{-8} \mathrm{sec}$, while $\tau_{A} \approx 6 \times 10^{-7} \mathrm{sec}$ for $399.2 \mathrm{~nm}$ line). The experimental error mainly comes from shot to shot fluctuation. In order to reduce it, an oscilloscope was used to monitor the discharge current. Shots, whose discharge current deviated from the average value more than $5 \%$, were disregarded. A 
set of spectra, which included 10-20 shots, were obtained under the same conditions and then averaged. The background in the averaged spectra remained the same for laser "on" and "off" conditions, and varied very little from day to day. The measurements under each condition were repeated many times. Altogether about 100 shots were taken and averaged for each condition. The standard deviations were about $1-2 \%$.

According to the previous experimental results, 8 the ratio of the peak height to the integral of the spontaneous emission lines remained the same for laser "on" and "off" conditions. Therefore, the branching ratios of the lines of interest were obtained from the ratios of the peak heights of the lines. In order to check that the ratios of the line integrals are equal to the ratios of the peak heights, several of the averaged data were chosen and both ratios were measured. The difference between them was less than $1 \%$. One should expect such good agreement because the instrumental broadening $\left(\Delta \lambda_{\text {instr }}=1.3 \AA\right)$ was much larger than the line broadening (by a factor of 30 ), hence the peak of the line intensity already quite closely corresponds to the integral intensity.

The same measurements of the branching ratio were repeated many times with different high voltage and argon base pressure applied to the discharge tube. By varying argon pressure and high voltage we could change the population of the Ar II ion levels. In this way we could increase, decrease or keep unchanged the intensity of the $442.6 \mathrm{~nm}$ line when the laser was switched on. However, independent of $442.6 \mathrm{~nm}$ line intensity behavior, we have observed the same change of branching ratio $R$, for the same power density of $514.5 \mathrm{~nm}$ radiation which eliminates absorption as a potential cause of the effect. Additionally, the self absorption of the spontaneous emission of the stronger line $(442.6 \mathrm{~nm})$ in the short discharge tube is less than $4 \%$, therefore, it cannot account for the $12 \%$ change of the intensity branching ratio observed.

The dependence of the observed quenching effect on the polarization of the spontaneous emission lines was checked as well by placing a polarizer in front of the entrance slit of the 
spectrometer. No change in quenching effect was observed when the polarizer was rotated.

In order to check that the observed quenching effect is not just related to a particular upper level, the branching ratio of another pair of spontaneous emission lines originating from a different common upper level was measured. The $378.6 \mathrm{~nm}$ and $422.8 \mathrm{~nm}$ lines are two ArII spontaneous emission lines having the same upper level $4 p{ }^{2} D^{\circ}{ }_{5 / 2}$ as the $488.0 \mathrm{~nm}$ lasing line of argon ion laser (see Fig. 3). Spectra of the spontaneous emission from the. short tube were taken with the argon ion laser did not lasing, lasing at $488.0 \mathrm{~nm}$, and lasing at $514.5 \mathrm{~nm}$. When the argon ion laser was tuned from nonlasing to lasing at $488.0 \mathrm{~nm}$ with lasing power of $3.6 \mathrm{~W}$, the intensity of the $378.6 \mathrm{~nm}$ line decreased about $5 \%$ while the intensity of the stronger $422.8 \mathrm{~nm}$ line decreased about $1.5 \%$. Therefore, the intensity branching ratio of the $378.6 \mathrm{~nm}$ to the $422.8 \mathrm{~nm}$ lines decreased about $4 \%$. This quenching effect is smaller (as expected) than that for $399.2 \mathrm{~nm}$ and $442.6 \mathrm{~nm}$ lines because the difference between $A$ coefficients for the $378.6 \mathrm{~nm}$ and the $422.8 \mathrm{~nm}$ lines is smaller (by factor of 5).

When the argon ion laser was lasing at $514.5 \mathrm{~nm}$, no change in the branching ratio of the $378.6 \mathrm{~nm}$ to the $422.8 \mathrm{~nm}$ lines was observed. This fact is consistent with previous results.

\section{Summary}

In order to exclude the effect of change in self absorption on observed changes in branching ratios we have measured relative intensities of spontaneous emission lines from a short discharge tube in which absorption for all lines of interest was negligible. The observed changes of branching ratio due to the presence of high-intensity photon flux provides support for the idea of a changing of Einstein A-coefficient for atoms or ions in strong electromagnetic fields. In order to show that this quenching effect is not just related to one particular level we have measured 
the branching ratio for another pair of spontaneous emission lines which originate from a different common upper level. The same type of quenching effect was observed.

\section{Acknowledgments}

We are thankful to $W$. Lee for his important contribution at the earlier stage of the work. We would like to express our appreciation to C. H. Skinner and J. L. Schwob and W. Tighe for their very stimulating discussions, and to $v$. Tkach for his very skillful technical assistance. We would also like to thank $H$. Griem for his very valuable comments on line pressure broadenings and the precision of intensity measurements. 


\section{References}

1. V. Weisskopf and E. Wigmer, Z. Phys. 63, 54 (1930) [Translated in Atomic Spectra, by W. R. Hindmarsh (Pergamon, London, 1967), p. 304 ].

2. L. I. Schiff, "Quantum Mechanics", McGraw-Hill, N.Y., 1959;

also B. H. Bransden and C. J. Joachain, "Physics of Atoms and Molecules," Longman, London and New York, 1983.

3. Y. Chung, P. Lemaire, S. Suckewer, Phys. Rev. Lett. 60, 1122 (1988).

4. Y. Chung, H. Hirose, S. Suckewer, Phys. Rev. A 40, 7142 (1989).

5. F. Aumayr, J. Hung, S. Suckewer, Phys. Rev. Lett. 63, 1215 (1989).

6. H. R. Griem, Phys. Rev. Lett. 66, 521 (1991); also Y.W. Huang et al., Phys. Rev. Lett. 65, 1757 (1990).

7. H.R. Griem et al., Phys. Fluids B, 3, 2430 (1991).

8. F. Aumayr, W. Lee, C. H. Skinner, S. Suckewer, J. Phys. B: 24 4489 (1991).

9. S. Suckewer, Phys. Fluids B, 3, 2437 (1991). 


\section{Figure Captions}

Fig 1. Schematic of experimental setup.

Fig. 2. Spectra of spontaneous emission from the short discharge tube in the vicinity of the $399.2 \mathrm{~nm}$ line (a) and in the vicinity of the $442.6 \mathrm{~nm}$ line (b). Shaded areas of the lines are those related to the quenching effect when laser was "on" at $514.5 \mathrm{~nm}$.

Fig 3. Partial ArII energy level diagram related to $488 \mathrm{~nm}$ lasing line with A-coefficients in units of $10^{7} \mathrm{sec}^{-1}$.

Fig 4. Normaiized intensity branching ratio $R=I_{399.2} / I_{442.6}$ as a fun tion of intra-cavity laser power density for $514.5 \mathrm{~nm}$ lasing line. 


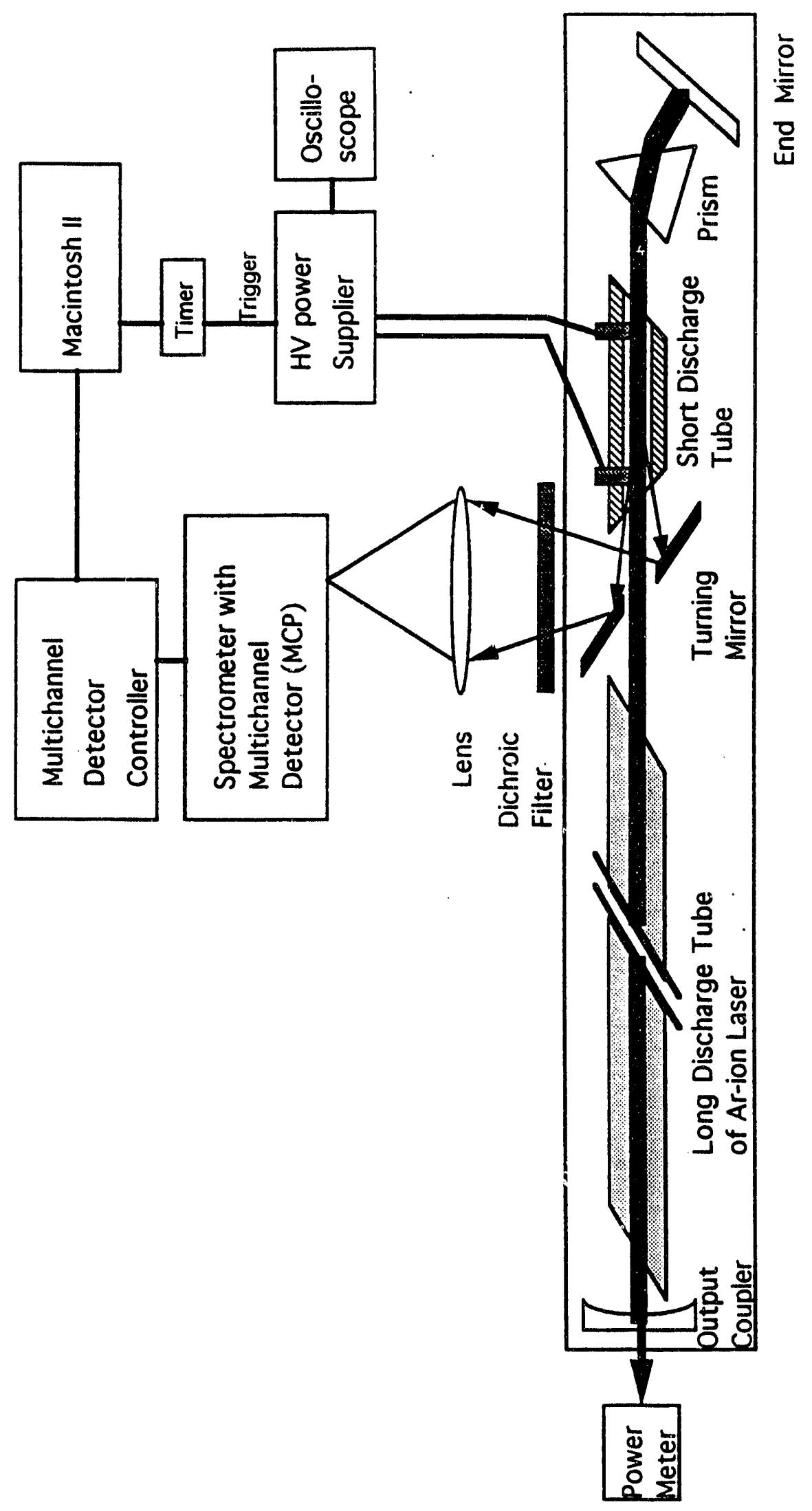

$\overline{9}$ 


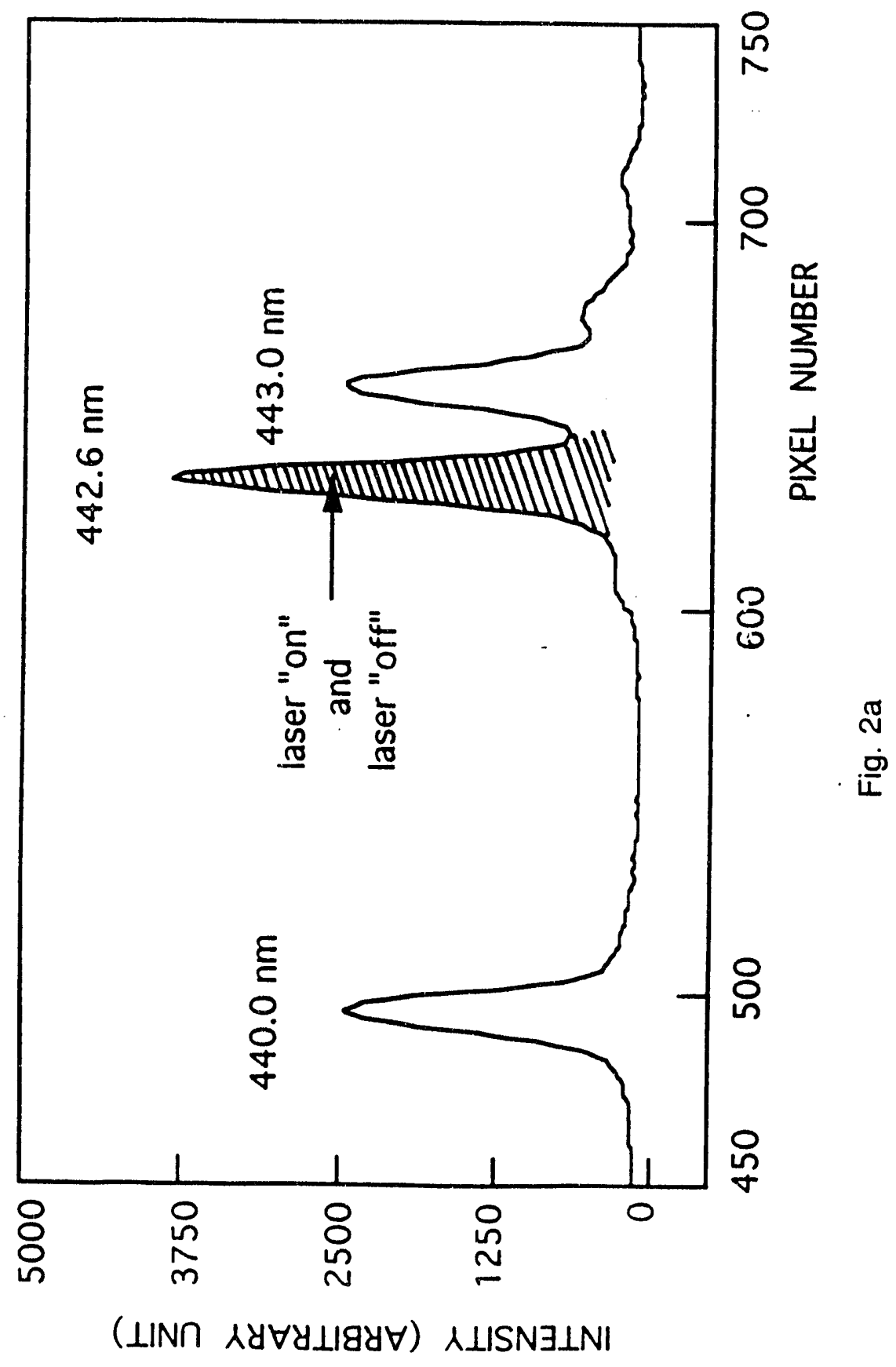




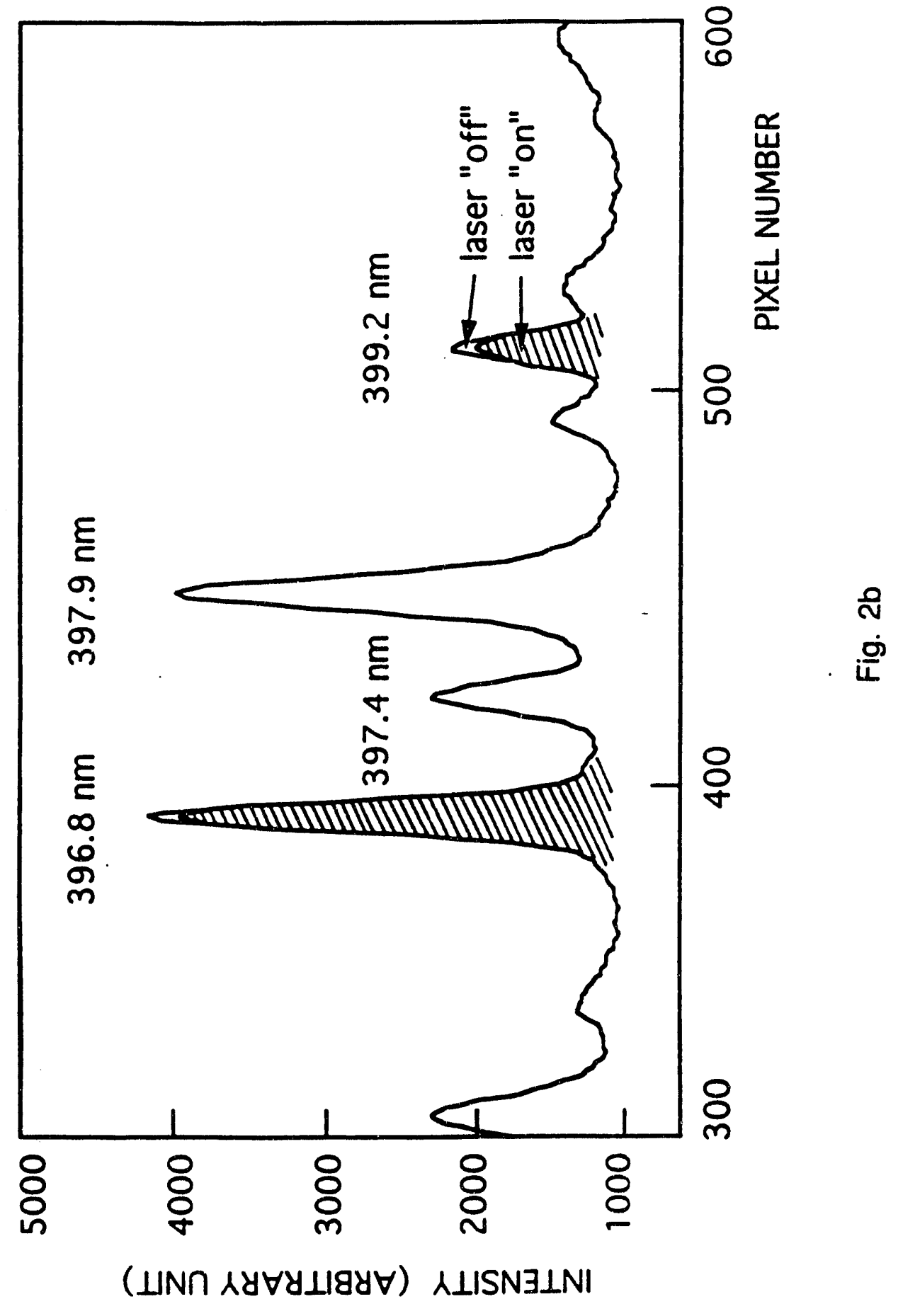




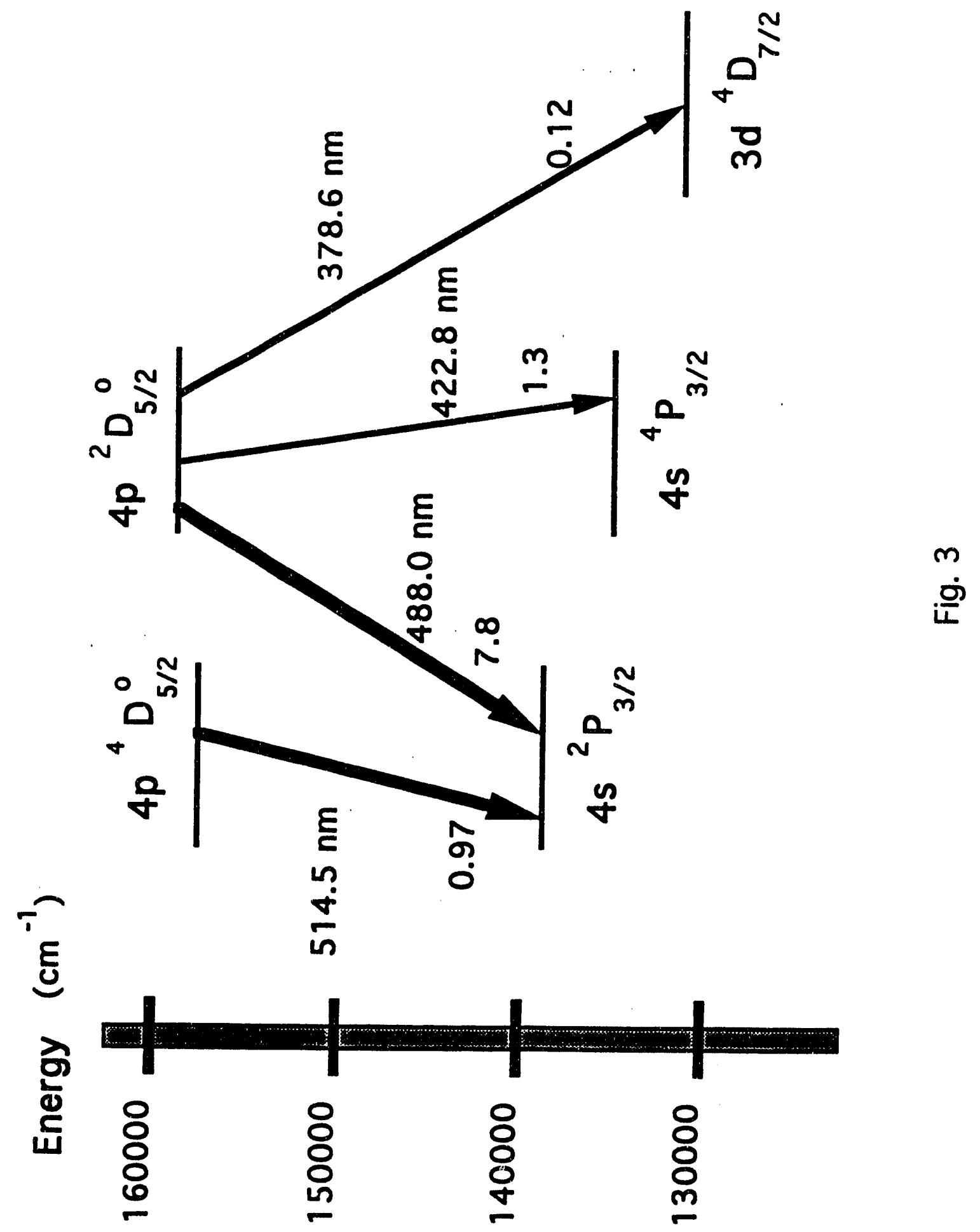




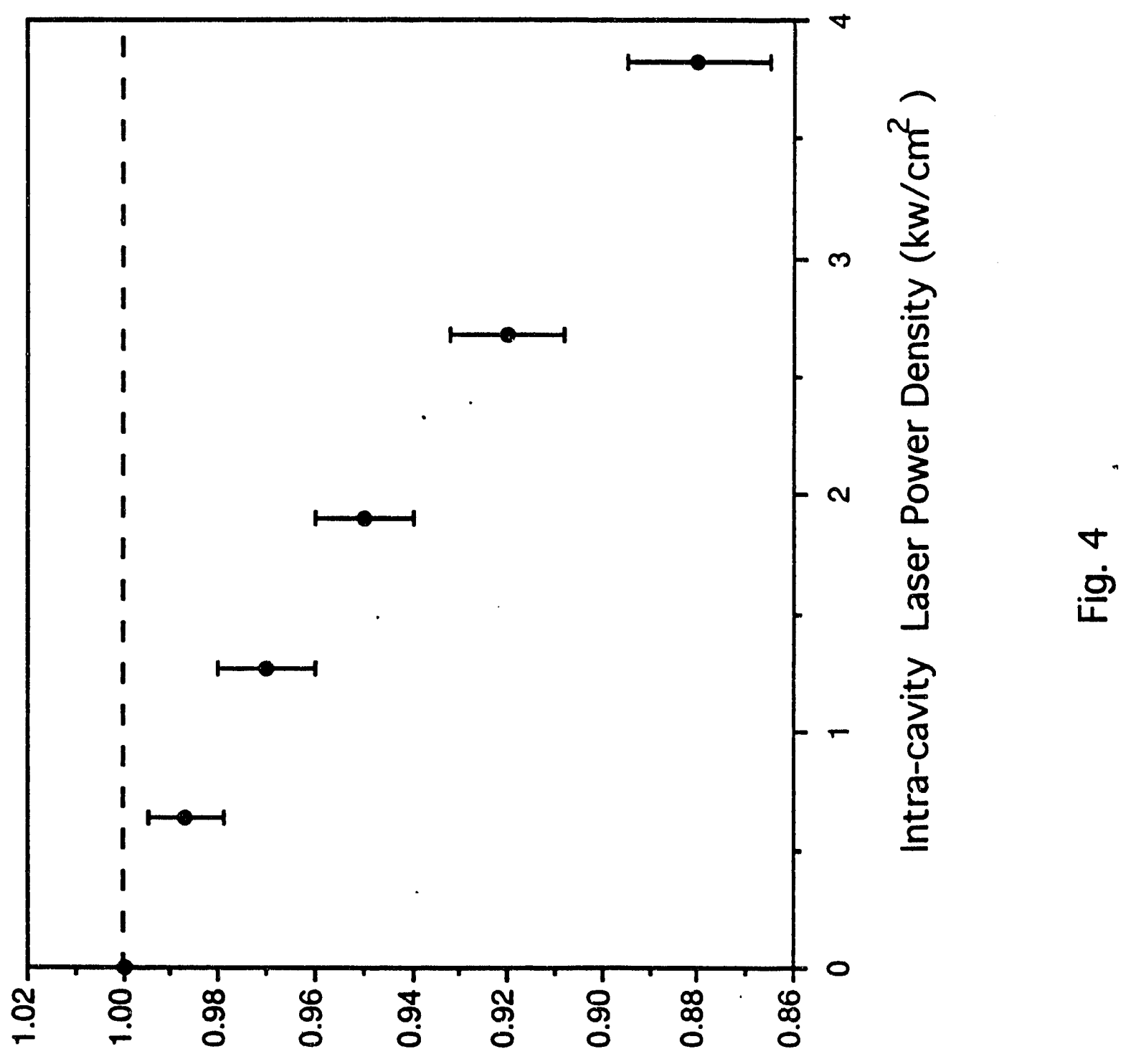

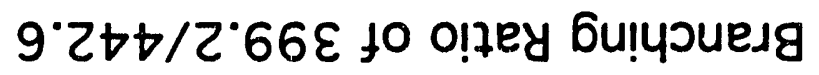


Dr. F. Peotoni, Univ. of Wollongong, AUSTRALLA

Prof. M.H. Breman, Univ. of Sydney, AUSTRALLA

Plasma Rocearch Leb., Australion Nat. Univ., AUSTRALLA

Prof. I.R. Jonee, Finders Univ, AUSTRALlA

Prof. F. Cep, Inst for Theoreticad Phycics, AUSTRIA

Prof. M. Heindiser, Inatiut for Theoretiecto Phyaik, AUSTRLA

Prot. M. Goosesens, Aletronomiech Insture, BELGIUM

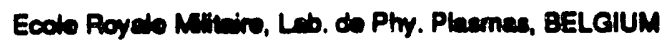

Commizcion-Europeen, DG. XII-Fusion Prog., BELGIUM

Prof. P. Bouciqub, Retkeuniveraibit Gent, BELGIUM

Dr. P.H. Saknake, motituo Fnica, BRAZL

Intituto Neciond De Pesquiese Especirit-INPE, BRUZIL

Documents Orico. Alomic Energy of Cenada Led., CANAOA

Dr. M.P. Bechyneld, MPB Technolocion, Ine., CANADA

Dr. H.M. Skersord, Univ. of Sackatchewen, CAMAOA

Prot. J. Teictumem, Univ. of Montered, CANADA

Prot. S.R. Sreanivecen, Univ. of Cologry, CaNADA

Prot. T.W. Johneton, INRS-Energie, CANAOA

Dr. R. Bowon, Centre conscien de tusion meonstique, CAMAOA

Dr. C.R. Jemen, Univ. of Abortm, CAMADA

Dr. P. Luklia Komenektho Univenatie, CZECHO-SLOVAKIA

Tho Lubrerien, Cuhan Leboratory, ENGLAND

Library, R61, Ruthertord Appleion Leboriony, ENGLAND

Mrs. S.A. Hulchineon, JET Lbrey, ENGLAND

Dr. S.C. Shema, Univ. of Soun Pecific, FWl ISLANDS

P. Munonen, Univ. of Helcinidy, FINLAND

Prot. M.N. Busecec, Ecolo Potyrachniono. FRANCE

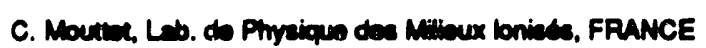

J. Pador CENCADARACHE - Ban 500, FRANCE

Prot. E. Econownen, Unir. of Crom, CREECE

M. C. Pind, Uniw. of lonumina, CREECE

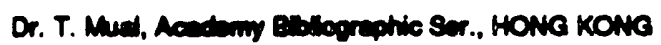

Prepoint Librey. Hunieation Acadermy of Sal. HUMCARY

Dr. B. Descupen, Secha thet of Nucter Phycices, INOIA

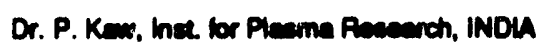

Dr. P. Rosenew, lersed inet of Tochrology, ISRAEL

Librerien, Intamationd Comar for Theo Phyrics, ITALY

Mise C. Do Palo, Asecociazion EURATOMENEA, ITALY

Dr. G. Groses, lettuto of Ficica ded Plasma, ITALY

Prof. G. Rostenoni, latulo Ges lonizzes Dal Cnr, ITALY

Dr. H. Yemeno, Tochiba Res dond Commer, JaPAN
Prof. I. Kewakeni, Hroshima Univ., JAPAN

Prot. K. Nichikewe, Hrochim Univ., LAPAN

Director, Jepen Atomic Energy Pocourch Inst, JAPAN

Prof. S. Itoh, Kyuahu Univ., JAPAN

Preserch into. Cr., National Instit for Fusion Scionco, JAPAN

Prot. S. Tencta, Kyow Univ., JAPAN

Libreys, Kyow Univ., JAPAN

Prof. N. Inoun, Univ. of Tolyo, JAPAN

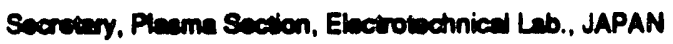

8. Mori, Techniced Adviecr, LAER, LAPAN

Dr. O. Mund, Kumanots inst of Technology, JAPAN

J. Hyeon-Sook, Korea Atomic Eneroy Rosearch inst, XOREA

D.I. Chad, Tho Korwa Adv. Inet of Sod. Tech., KOREA

Prot. B.S. Liby, Univ. of Waikas. NEW ZEALAND

Inte of Phyeica, Chinew Acad SA PEOPLE'S REP. OF CHINA

Librery, Inte of Piama Phyeica, PEOPLE'S REP. OF CHIMA

Thinghun Univ. Librery, PEOPLE'S REPUBUC OF CHIM

Z U, S.W. Inet Plyyics, PEOPLE'S REPUBLIC OF CHIM

Prof. J.A.C. Cebre, Inetiut Suparior Teconico, POATUGAL

Dr. O. Petus, Al I CUzA Univ., Romania

Dr. J. do Vimien, Fusion Suctios, AEC, S. AFRICA

Prot. M.A. Hemoerg, Univ. of Nated, S. AFRiCA

Prot. D.E. Km, Pohuno ince. of Sad. Tech., SO. KOREA

Prot. C.I.E.MA.T, Fution Divicion Library, SPAN

Dr. L Simfio, Univ. of UMEA, SWEDEN

Librery, Royd inat of Tectinology, SWEDEN

Prot. H. Writemeon, Chamere Univ. of Tech., SWEDEN

Centre Phys. Des Ptaenas, Ecolo Polyech, SWITZERLAND

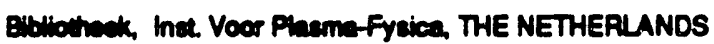

Aest Prot. Or. S. Codr, Midds East Tech. Univ., TUAKEY

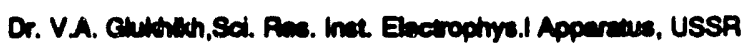

Dr. D.D. Ayutow, Stberien Brench of Academy of Soi., USSA

Dr. G.A. Elanew, I.V. Kurchatov Inat, USSA

Librerion, The Uler.SSA Acedemy of Scionces, USSA

Or. LM. Kowriatunyth, Inat, of Cenend Phyzica, USSA

Kentorectungeantegs GmbH, Zentrabibiotheck, W. GEPMANY

Bibliothate, Inst. For Pisematorschung, W. GERMANY

Prof. K. Schincier, Ruhr-Univeraitu Bochum, W. GERMANY

Dr. F. Weoner, (ASDEX), Max-Plenct-Inetieut, W. GERMANY

Librerion, Maxflunct-1natitu, W. GEPMANY

Prot. R.K Jenew, Inate of Phyaics, rucosLava 

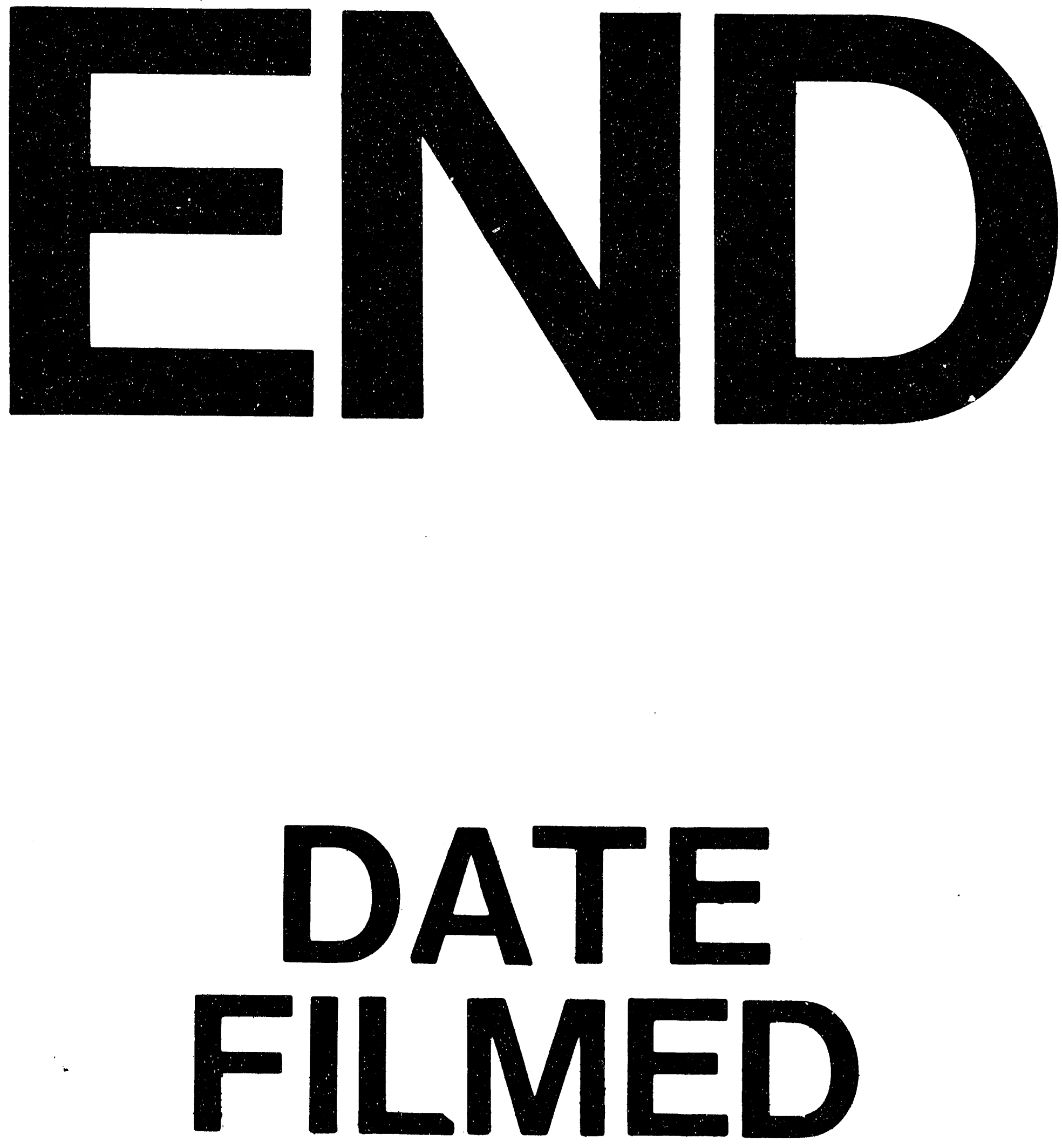

1

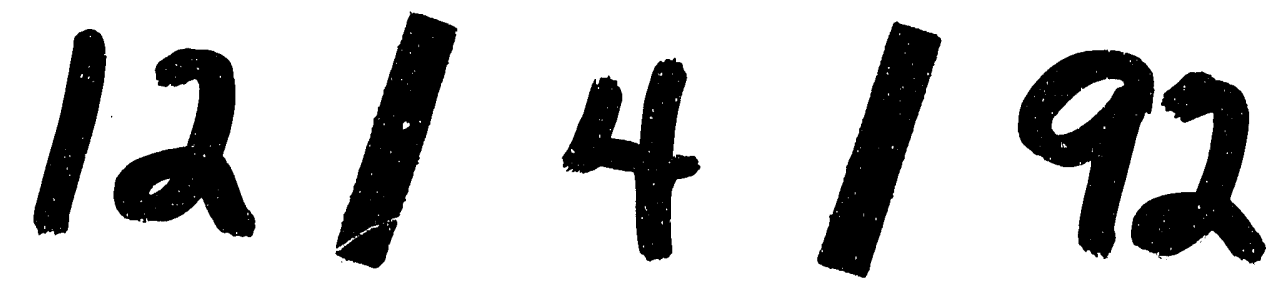




\title{
Quenching A-coefficients by photons in a short discharge tube
}

PPPL--2861

DE93 002630

\author{
H. Cao, D. DiCicco and S. Suckewer \\ Dept of Mechanical and Aerospace Engineering \\ and Plasma Physics Laboratory \\ Princeton University, Princeton, NJ 08544.
}

\begin{abstract}
New experimental results on quenching of A-coefficients by photons in a short discharge tube are presented. Experiments with the short discharge tube have eliminated questions related to the effects of absorption in a long laser tube, and have provided good confirmation of earlier results.

\section{Introduction}

Einstein $A$ and $B$ coefficients are treated as constant coefficients for atoms and ions. For isolated atoms and ions this is true, as was shown many years ago by Weisskopf and Wigner, 1 and the Fermi Golden Rule formula may be directly applied (see e.g., Ref. 2). However, for atomic systems which are not isolated but under the influence of electromagnetic field, which perturb them on a time scale $\tau$ much shorter than $\tau_{A}=A^{-1}$, the assumptions on which the Fermi Golden Rule formula is based might be violated.2 Hence, in such a case $A$ and $B$ values may not be the same as for isolated atomic systems. For example, in plasmas one would expect quenching of $A$ (as well as B) coefficients for transitions for which $\tau_{A} \gg \tau$, where $\tau$ in this case is determined by the frequency of inelastic collisions between electrons and atoms or ions.3.4 A similar effect could be expected also for atoms and ions under frequent "collisions"
\end{abstract}


with photons, e.g., in relatively high power density laser beams (quenching A-coefficients by photons ${ }^{5}$ ).

One of the major issues raised by Hans Griem6,7 concerning our paper on quenching A-coefficients by photons 5 was the question of power broadening of stronger lines and the related effect of the decrease of the absorption of these lines in a long discharge laser tube. Although some of our measurements and calculations indicated that this should not be the case, ${ }^{7}$ we believed direct experimental evidence would be the best indicator of the validity of this explanation. Our approach was to place a short diccharge tube, in which the absorption is egligible for all lines of interest, inside a laser cavity. This configuration eliminates the possible change of absorption for stronger lines. Another advantage of a short discharge tube placed inside the laser cavity is that one may change discharge conditions in the tube, leading to the change of levels population, without changing the power density in the resonator.

In this new experiment we also replaced our previous one-channel type detectors on spectrometers with multichannel detector. This allowed us to monitor simultaneously lines for which quenching of A-coefficients could occur and those for which quenching was not expected.

\section{Experimental Arrangement}

Figure 1 shows the experimental setup. A short discharge tube filled with argon gas was placed inside the cavity of an argon ion laser (COHERENT-Innova 200). The reason for placing the short tube inside the cavity was that the photon flux inside the cavity was much higher and more uniform than that obtainable outside the cavity. The effective length of the discharge tube was $4.5 \mathrm{~cm}$ and its inner diameter was $5 \mathrm{~mm}$. Discharges in the short tube were created in a pulsed fashion to avoid overheating. Rogowski coil connected to an oscilloscope was used to monitor the discharge current. The short tube was cut 
at Brewster angle on its ends in order to reduce losses inside the laser cavity introduced by this tube.

A high reflectivity mirror with a $4 \mathrm{~mm}$ hole in its center was placed inside the laser cavity and tilted at 45 degree to the laser beam path. While the laser beam, $2 \mathrm{~mm}$ in diameter, could pass through the hole of the mirror and oscillate inside the cavity, the spontaneous emission from the short discharge tube could be reflected by the mirror out of the cavity. The spontaneous emission from the short tube was focused onto the eritrance slit of the spectrometer by achromatic lens. A dichroic filter was used to block the scattered laser light. The argon ion laser was tuned for lasing at a particular lasing line or to nonlasing by rotating the prism and the end-mirror. In this way it was possible to control the photon density inside the cavity over a large range. The intra-cavity photon density was monitored by measuring the laser output power.

The spectrometer was a $0.5 \mathrm{~m}$ Ebert-Fastie type JarrellAsh monochromator with a 1200 groove $/ \mathrm{mm}$ holographic grating. In order to make the lines of interest well separated from their neighboring lines, the width of the entrance slit was set at $10 \mu \mathrm{m}$ and the spectrum was observed in second order. At the exit of the spectrometer a multichannel detector head (Princeton Instruments, Model IRY-700) was installed. The multichannel detector controller was used to control the gating system of the detector head and transmit the data (spectra) to an Apple Macintosh II.

The synchronization between discharges in the small tube and data acquisition system was accomplished by computer control of the experimental operation. The detector head was gated open for the time of the discharge and the first spectrum was recorded. After the discharge, the detector head was gated open again for the same amount of exposure time in order to record the background spectrum. The final spectrum was obtained by subtracting the background spectrum from the discharge spectrum.

Since the laser light had no effect on argon ions or atoms outside the beam path, it was crucial in this experiment 
to image on the entrance slit of the spectrometer only the part of argon gas, which was in the laser beam path. In order to satisfy this condition, the height of the entrance slit had to be carefully masked followed by fine alignment of the focusing lens.

Although the spontaneous emission from the long discharge tube was much stronger than that from the short tube, most of it was reflected by the back side of the $45^{\circ}$ mirror and traveled away from the spectrometer. A very small part of this radiation, which was reflected by the end-mirror and entered the spectrometer, was much weaker (by factor of 5-10) than that from the short tube. Because the discharge in long tube was running in continuous mode, its spontaneous emission spectrum played the same role as a background radiation and therefore canceled after substraction in the final spectrum. A number of spectra were taken under the same experimental conditions and were averaged in order to minimize the shot-toshot fluctuations.

Finally, the possibility of nonlinear response of the detector or optical components due to the laser beam power has been checked (similarly as in. Ref. 8) and excluded as a potential cause of error.

\section{Experimental Results}

As a first step in our experimental program we measured the intensity branching ratio of Ar II $399.2 \mathrm{~nm}$ and $442.6 \mathrm{~nm}$ lines in the laser discharge tube. Both transitions are from the common upper $4 p{ }^{4} D_{5 / 2}$ level down to $3 d{ }^{4} D_{3 / 2}$ and $4 s{ }^{4} P_{3 / 2}$ levels, respectively, with A-coefficients for unperturbed ions being about 50 times lower for the $399.2 \mathrm{~nm}$ line than for the $442.6 \mathrm{~nm}$ line. (Partial energy diagrams for these and other ArII transitions of interest for this work as well as discussion of A-coefficients for non-perturbed ArII ions were presented in earlier papers 5,8 ). These were practically the same type of measurements as those presented earlier 8 except that in this work the spectra were recorded with a multichannel detector 
instead of a single line intensity measurements with photomultiplier. Measurements were performed for a different laser beam power at wavelength $514.5 \mathrm{~nm}$. The results obtained were in excellent agreement with earlier results. ${ }^{8}$

In the next step we proceeded with our experiments with a short discharge tube. In Fig. 2a,b a typical set of spontaneous emission spectra from short discharge tubo with Ar-ion laser "on" and "off" ("lasing" and "nonlasing" conditions) is shown. The spectra for laser "on" were obtained with beam power $\sim 4.4 \mathrm{~W}$ for $514.5 \mathrm{~nm}$ lasing line. While the intensity of $442.6 \mathrm{~nm}$ line (Fig. 2a) remained almost the same during "lasing" and "nonlasing," the intensity of the $399.2 \mathrm{~nm}$ line (Fig. 2b) decreased $\sim 8 \%$ when the argon ion laser was lasing at $514.5 \mathrm{~nm}$ resulting in the decrease of the intensity branching ratio $R=I_{399.2} / I_{442.6}$. Another spontaneous emission line $(396.8 \mathrm{~nm})$ in Fig. 2b, also having the same upper level as $514.5 \mathrm{~nm}$ lasing line, decreased about $4 \%$ in its intensity under lasing conditions. This change agreed with our earlier hypothesis 5,8 that quenching is smaller for lines with larger Acoefficients. For all other neighboring lines with different upper levels from the $514.5 \mathrm{~nm}$ line we did not observe any intensity changes. This confirms that the observed changes were not due to statistical fluctuations. The intensity branching ratio of the $399.2 \mathrm{~nm}$ and $442.6 \mathrm{~nm}$ lines was also measured when the argon ion laser was lasing at another lasing line $(448.0 \mathrm{~nm}$, see Fig. 3). No change in this branching ratio was observed, which is in agreement with earlier measurements. 8

Figure 4 presents the branching ratio $R=I_{399.2} / I_{442.6}$ (normalized to 1 for non-lasing condition) versus intra-cavity laser power density at $514.5 \mathrm{~nm}$. As the photon flux increased, the branching. ratio decreased. The largest decrement observed in this experiment was $\sim 12 \%$. (Note: for power density $4 \mathrm{~kW} / \mathrm{cm}^{2}$ at wavelength $514.5 \mathrm{~nm}$ the $\tau \approx 4 \times 10^{-8} \mathrm{sec}$, while $\tau_{A} \approx 6 \times 10^{-7} \mathrm{sec}$ for $399.2 \mathrm{~nm}$ line). The experimental error mainly comes from shot to shot fluctuation. In order to reduce it, an oscilloscope was used to monitor the discharge current. Shots, whose discharge current deviated from the average value more than $5 \%$, were disregarded. A 
set of spectra, which included 10-20 shots, were obtained under the same conditions and then averaged. The background in the averaged spectra remained the same for laser "on" and "off" conditions, and varied very little from day to day. The measurements under each condition were repeated many times. Altogether about 100 shots were taken and averaged for each condition. The standard deviations were about $1-2 \%$.

According to the previous experimental results, 8 the ratio of the peak height to the integral of the spontaneous emission lines remained the same for laser "on" and "off" conditions. Therefore, the branching ratios of the lines of interest were obtained from the ratios of the peak heights of the lines. In order to check that the ratios of the line integrals are equal to the ratios of the peak heights, several of the averaged data were chosen and both ratios were measured. The difference between them was less than $1 \%$. One should expect such good agreement because the instrumental broadening $\left(\Delta \lambda_{\text {instr }}=1.3 \AA\right)$ was much larger than the line broadening (by a factor of 30 ), hence the peak of the line intensity already quite closely corresponds to the integral intensity.

The same measurements of the branching ratio were repeated many times with different high voltage and argon base pressure applied to the discharge tube. By varying argon pressure and high voltage we could change the population of the Ar II ion levels. In this way we could increase, decrease or keep unchanged the intensity of the $442.6 \mathrm{~nm}$ line when the laser was switched on. However, independent of $442.6 \mathrm{~nm}$ line intensity behavior, we have observed the same change of branching ratio $R$, for the same power density of $514.5 \mathrm{~nm}$ radiation which eliminates absorption as a potential cause of the effect. Additionally, the self absorption of the spontaneous emission of the stronger line $(442.6 \mathrm{~nm})$ in the short discharge tube is less than $4 \%$, therefore, it cannot account for the $12 \%$ change of the intensity branching ratio observed.

The dependence of the observed quenching effect on the polarization of the spontaneous emission lines was checked as well by placing a polarizer in front of the entrance slit of the 
spectrometer. No change in quenching effect was observed when the polarizer was rotated.

In order to check that the observed quenching effect is not just related to a particular upper level, the branching ratio of another pair of spontaneous emission lines originating from a different common upper level was measured. The $378.6 \mathrm{~nm}$ and $422.8 \mathrm{~nm}$ lines are two ArII spontaneous emission lines having the same upper level $4 p{ }^{2} D^{\circ}{ }_{5 / 2}$ as the $488.0 \mathrm{~nm}$ lasing line of argon ion laser (see Fig. 3). Spectra of the spontaneous emission from the. short tube were taken with the argon ion laser did not lasing, lasing at $488.0 \mathrm{~nm}$, and lasing at $514.5 \mathrm{~nm}$. When the argon ion laser was tuned from nonlasing to lasing at $488.0 \mathrm{~nm}$ with lasing power of $3.6 \mathrm{~W}$, the intensity of the $378.6 \mathrm{~nm}$ line decreased about $5 \%$ while the intensity of the stronger $422.8 \mathrm{~nm}$ line decreased about $1.5 \%$. Therefore, the intensity branching ratio of the $378.6 \mathrm{~nm}$ to the $422.8 \mathrm{~nm}$ lines decreased about $4 \%$. This quenching effect is smaller (as expected) than that for $399.2 \mathrm{~nm}$ and $442.6 \mathrm{~nm}$ lines because the difference between $A$ coefficients for the $378.6 \mathrm{~nm}$ and the $422.8 \mathrm{~nm}$ lines is smaller (by factor of 5).

When the argon ion laser was lasing at $514.5 \mathrm{~nm}$, no change in the branching ratio of the $378.6 \mathrm{~nm}$ to the $422.8 \mathrm{~nm}$ lines was observed. This fact is consistent with previous results.

\section{Summary}

In order to exclude the effect of change in self absorption on observed changes in branching ratios we have measured relative intensities of spontaneous emission lines from a short discharge tube in which absorption for all lines of interest was negligible. The observed changes of branching ratio due to the presence of high-intensity photon flux provides support for the idea of a changing of Einstein A-coefficient for atoms or ions in strong electromagnetic fields. In order to show that this quenching effect is not just related to one particular level we have measured 
the branching ratio for another pair of spontaneous emission lines which originate from a different common upper level. The same type of quenching effect was observed.

\section{Acknowledgments}

We are thankful to $W$. Lee for his important contribution at the earlier stage of the work. We would like to express our appreciation to C. H. Skinner and J. L. Schwob and W. Tighe for their very stimulating discussions, and to $v$. Tkach for his very skillful technical assistance. We would also like to thank $H$. Griem for his very valuable comments on line pressure broadenings and the precision of intensity measurements. 


\section{References}

1. V. Weisskopf and E. Wigmer, Z. Phys. 63, 54 (1930) [Translated in Atomic Spectra, by W. R. Hindmarsh (Pergamon, London, 1967), p. 304 ].

2. L. I. Schiff, "Quantum Mechanics", McGraw-Hill, N.Y., 1959;

also B. H. Bransden and C. J. Joachain, "Physics of Atoms and Molecules," Longman, London and New York, 1983.

3. Y. Chung, P. Lemaire, S. Suckewer, Phys. Rev. Lett. 60, 1122 (1988).

4. Y. Chung, H. Hirose, S. Suckewer, Phys. Rev. A 40, 7142 (1989).

5. F. Aumayr, J. Hung, S. Suckewer, Phys. Rev. Lett. 63, 1215 (1989).

6. H. R. Griem, Phys. Rev. Lett. 66, 521 (1991); also Y.W. Huang et al., Phys. Rev. Lett. 65, 1757 (1990).

7. H.R. Griem et al., Phys. Fluids B, 3, 2430 (1991).

8. F. Aumayr, W. Lee, C. H. Skinner, S. Suckewer, J. Phys. B: 24 4489 (1991).

9. S. Suckewer, Phys. Fluids B, 3, 2437 (1991). 


\section{Figure Captions}

Fig 1. Schematic of experimental setup.

Fig. 2. Spectra of spontaneous emission from the short discharge tube in the vicinity of the $399.2 \mathrm{~nm}$ line (a) and in the vicinity of the $442.6 \mathrm{~nm}$ line (b). Shaded areas of the lines are those related to the quenching effect when laser was "on" at $514.5 \mathrm{~nm}$.

Fig 3. Partial ArII energy level diagram related to $488 \mathrm{~nm}$ lasing line with A-coefficients in units of $10^{7} \mathrm{sec}^{-1}$.

Fig 4. Normaiized intensity branching ratio $R=I_{399.2} / I_{442.6}$ as a fun tion of intra-cavity laser power density for $514.5 \mathrm{~nm}$ lasing line. 


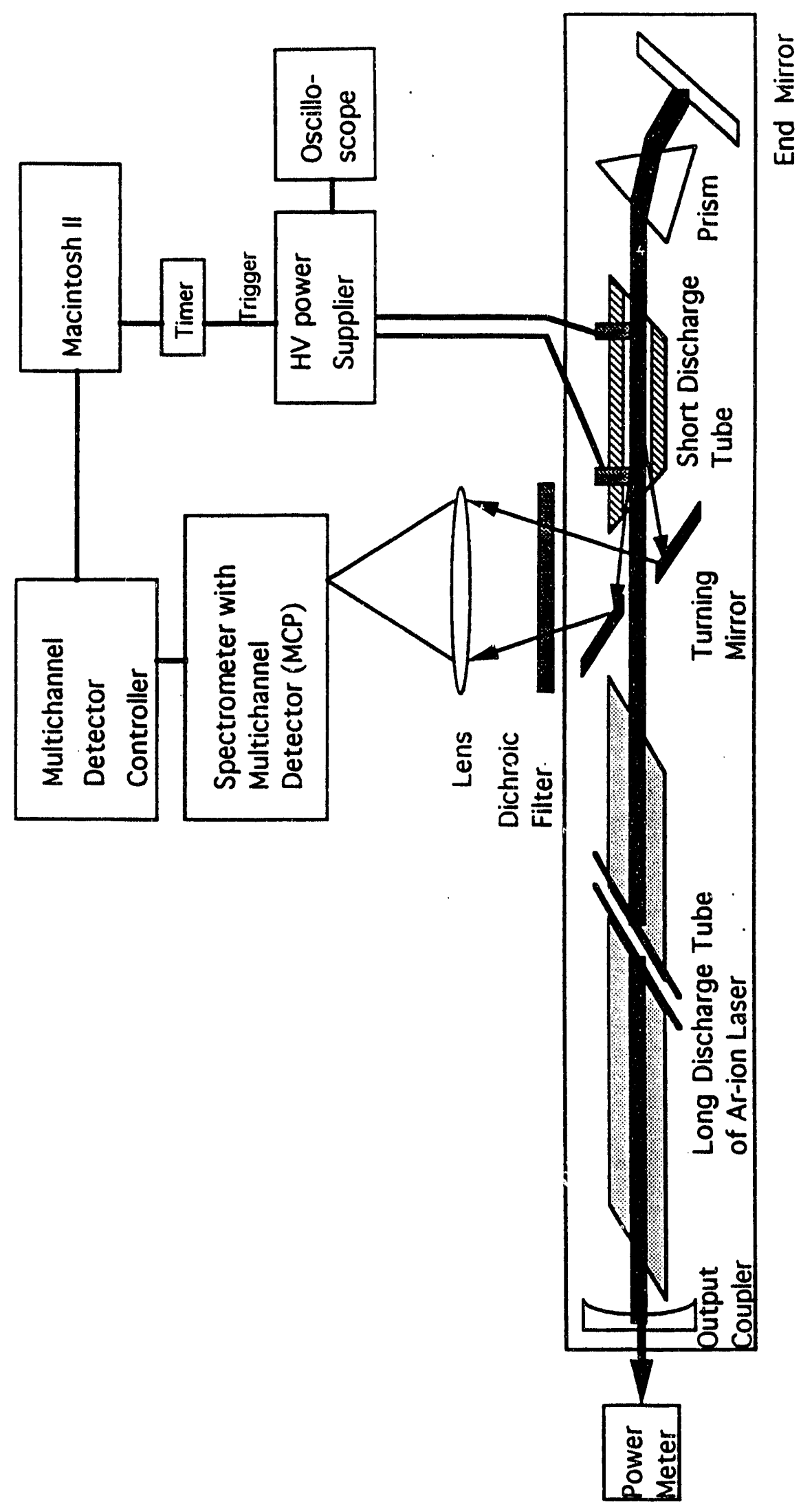

$\overline{9}$ 


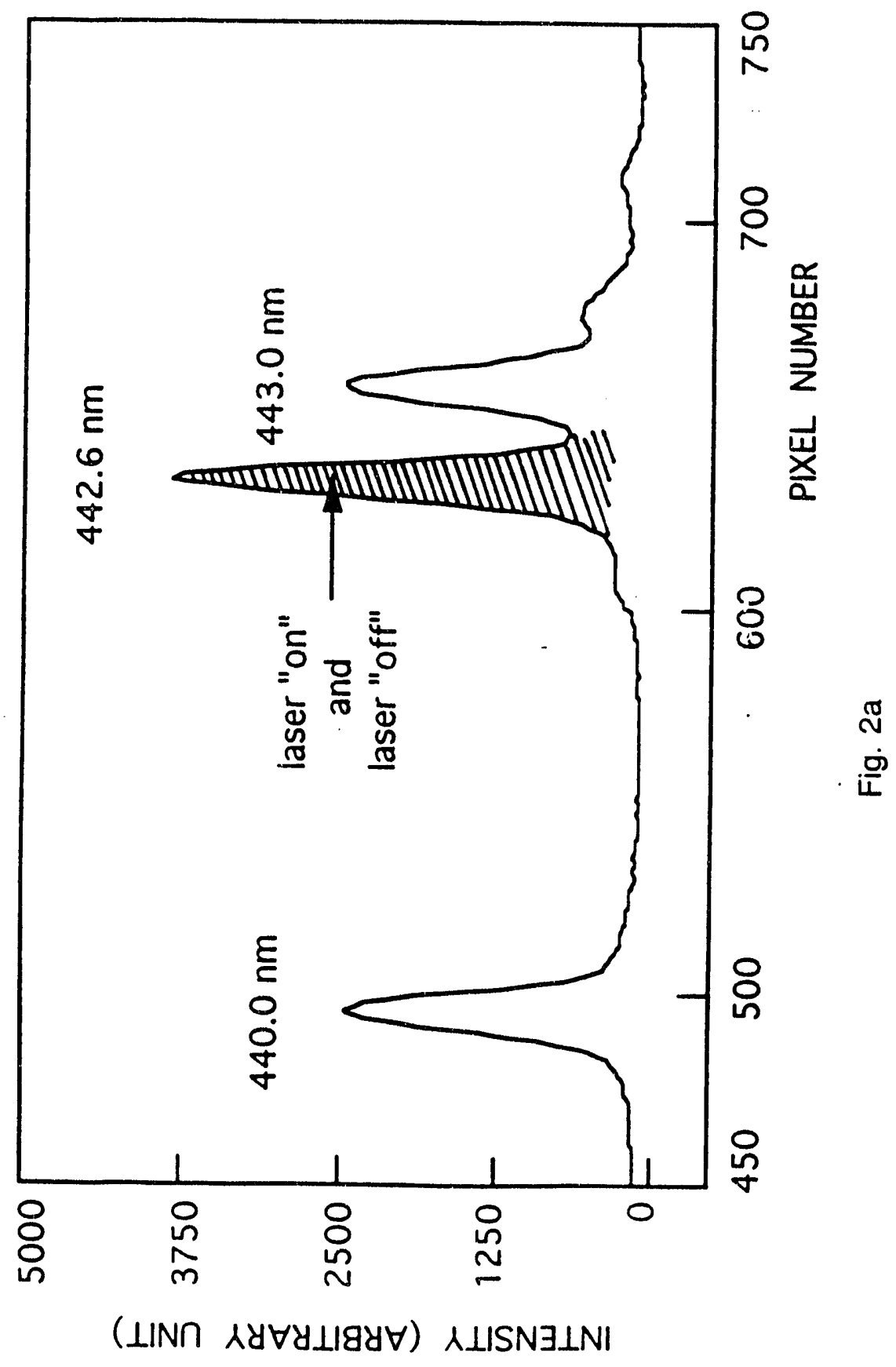




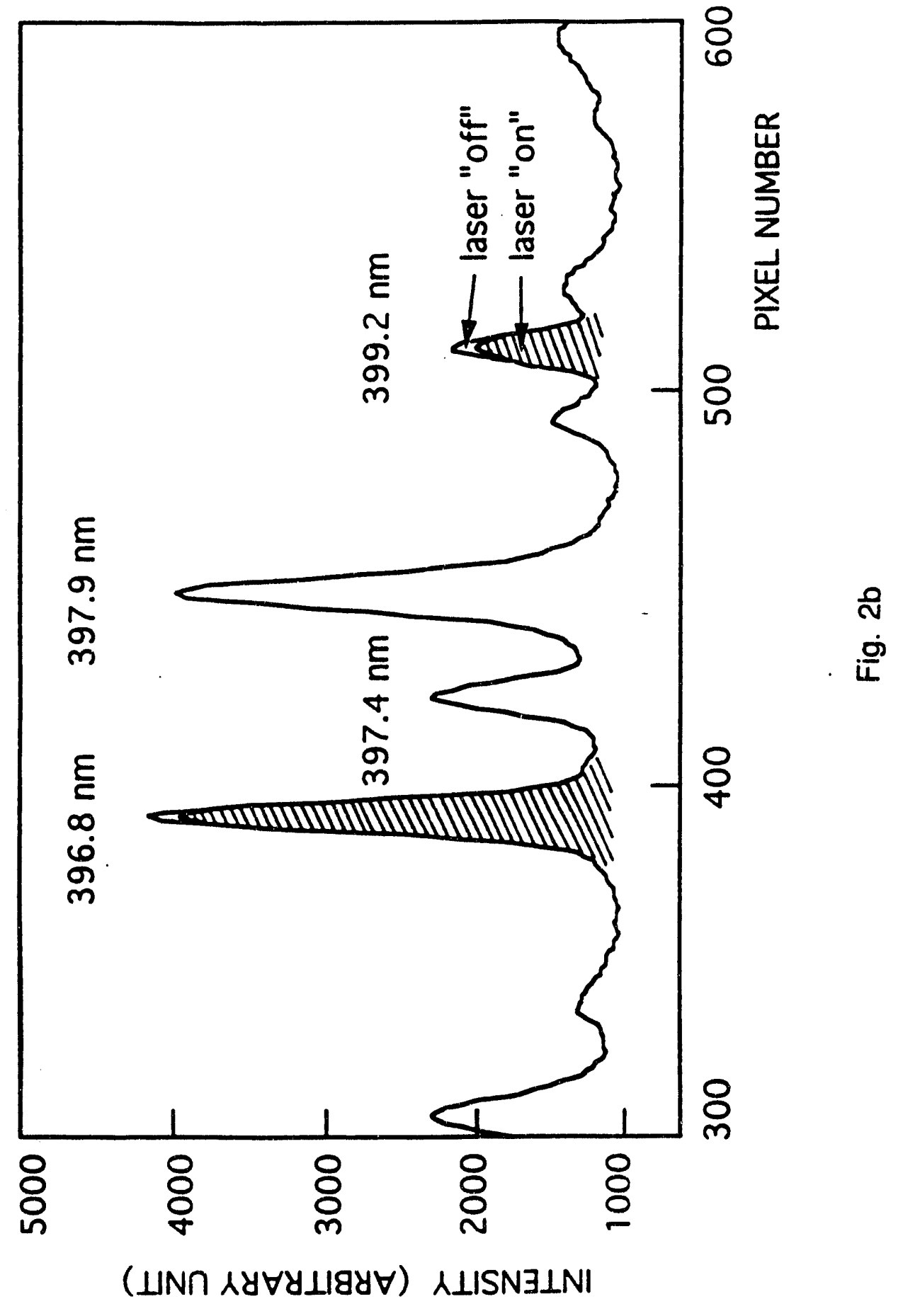




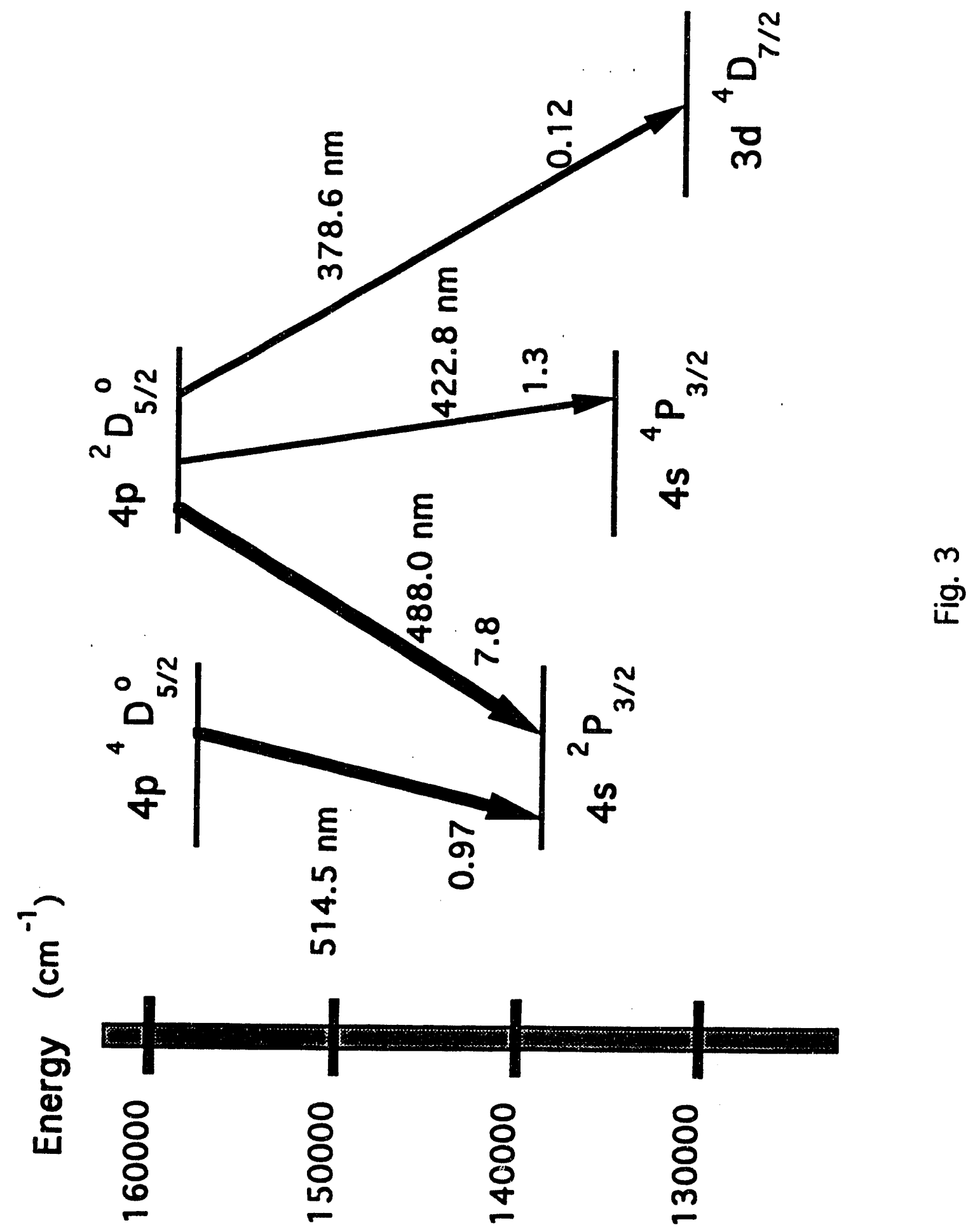




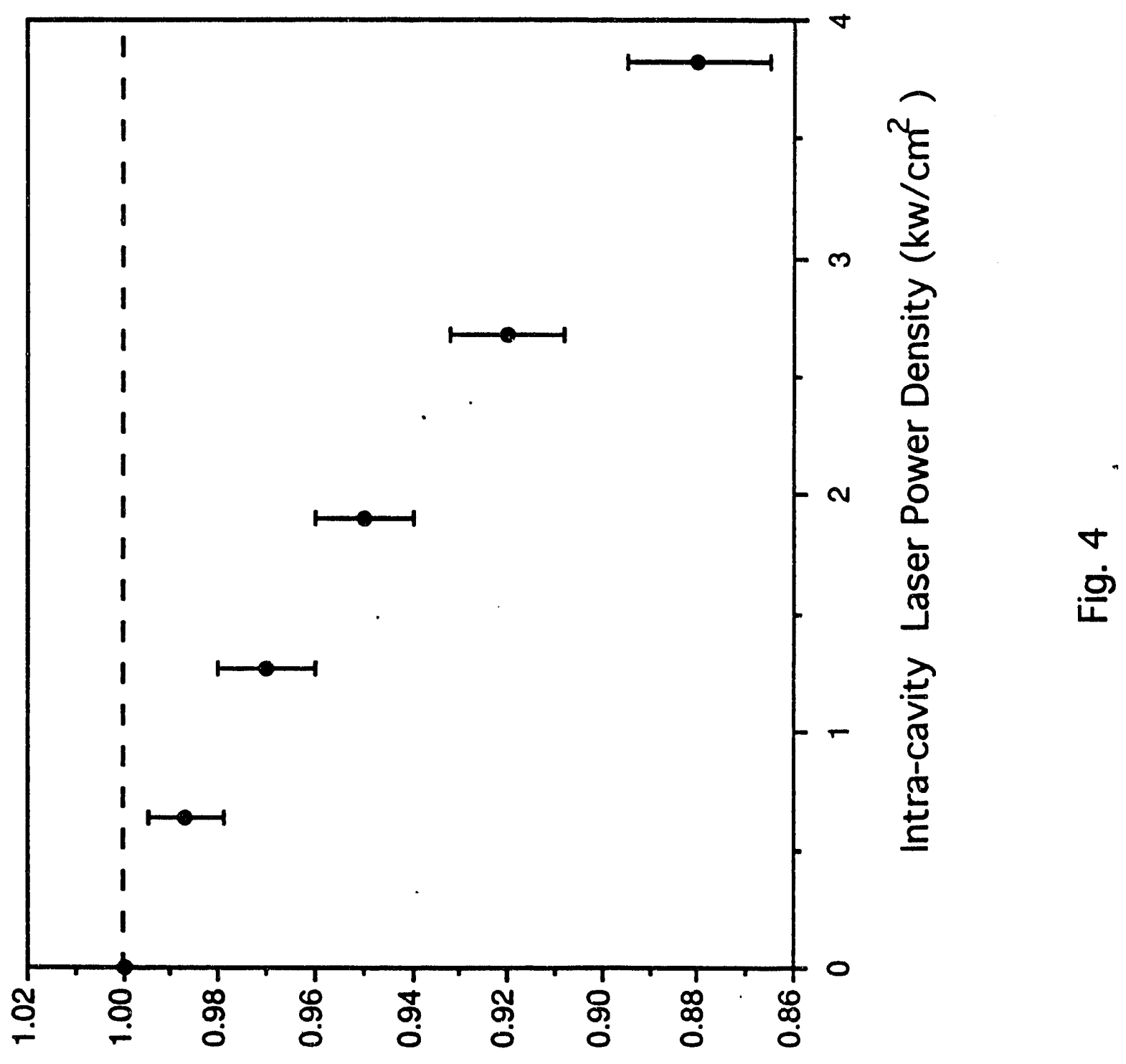

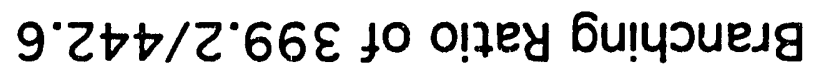


Dr. F. Peotoni, Univ. of Wollongong, AUSTRALLA

Prof. M.H. Breman, Univ. of Sydney, AUSTRALLA

Plasma Rocearch Leb., Australion Nat. Univ., AUSTRALLA

Prof. I.R. Jonee, Finders Univ, AUSTRALlA

Prof. F. Cep, Inst for Theoreticad Phycics, AUSTRIA

Prof. M. Heindiser, Inatiut for Theoretiecto Phyaik, AUSTRLA

Prot. M. Goosesens, Aletronomiech Insture, BELGIUM

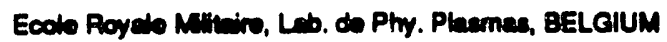

Commizcion-Europeen, DG. XII-Fusion Prog., BELGIUM

Prof. P. Bouciqub, Retkeuniveraibit Gent, BELGIUM

Dr. P.H. Saknake, motituo Fnica, BRAZL

Intituto Neciond De Pesquiese Especirit-INPE, BRUZIL

Documents Orico. Alomic Energy of Cenada Led., CANAOA

Dr. M.P. Bechyneld, MPB Technolocion, Ine., CANADA

Dr. H.M. Skersord, Univ. of Sackatchewen, CAMAOA

Prot. J. Teictumem, Univ. of Montered, CANADA

Prot. S.R. Sreanivecen, Univ. of Cologry, CaNADA

Prot. T.W. Johneton, INRS-Energie, CANAOA

Dr. R. Bowon, Centre conscien de tusion meonstique, CAMAOA

Dr. C.R. Jemen, Univ. of Abortm, CAMADA

Dr. P. Luklia Komenektho Univenatie, CZECHO-SLOVAKIA

Tho Lubrerien, Cuhan Leboratory, ENGLAND

Library, R61, Ruthertord Appleion Leboriony, ENGLAND

Mrs. S.A. Hulchineon, JET Lbrey, ENGLAND

Dr. S.C. Shema, Univ. of Soun Pecific, FWl ISLANDS

P. Munonen, Univ. of Helcinidy, FINLAND

Prot. M.N. Busecec, Ecolo Potyrachniono. FRANCE

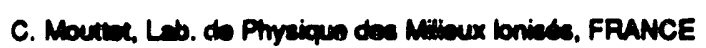

J. Pador CENCADARACHE - Ban 500, FRANCE

Prot. E. Econownen, Unir. of Crom, CREECE

M. C. Pind, Uniw. of lonumina, CREECE

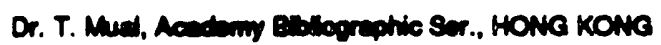

Prepoint Librey. Hunieation Acadermy of Sal. HUMCARY

Dr. B. Descupen, Secha thet of Nucter Phycices, INOIA

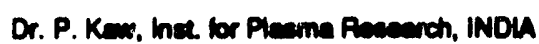

Dr. P. Rosenew, lersed inet of Tochrology, ISRAEL

Librerien, Intamationd Comar for Theo Phyrics, ITALY

Mise C. Do Palo, Asecociazion EURATOMENEA, ITALY

Dr. G. Groses, lettuto of Ficica ded Plasma, ITALY

Prof. G. Rostenoni, latulo Ges lonizzes Dal Cnr, ITALY

Dr. H. Yemeno, Tochiba Res dond Commer, JaPAN
Prof. I. Kewakeni, Hroshima Univ., JAPAN

Prot. K. Nichikewe, Hrochim Univ., LAPAN

Director, Jepen Atomic Energy Pocourch Inst, JAPAN

Prof. S. Itoh, Kyuahu Univ., JAPAN

Preserch into. Cr., National Instit for Fusion Scionco, JAPAN

Prot. S. Tencta, Kyow Univ., JAPAN

Libreys, Kyow Univ., JAPAN

Prof. N. Inoun, Univ. of Tolyo, JAPAN

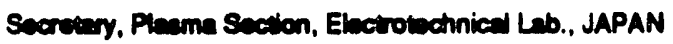

8. Mori, Techniced Adviecr, LAER, LAPAN

Dr. O. Mund, Kumanots inst of Technology, JAPAN

J. Hyeon-Sook, Korea Atomic Eneroy Rosearch inst, XOREA

D.I. Chad, Tho Korwa Adv. Inet of Sod. Tech., KOREA

Prot. B.S. Liby, Univ. of Waikas. NEW ZEALAND

Inte of Phyeica, Chinew Acad SA PEOPLE'S REP. OF CHINA

Librery, Inte of Piama Phyeica, PEOPLE'S REP. OF CHIMA

Thinghun Univ. Librery, PEOPLE'S REPUBUC OF CHIM

Z U, S.W. Inet Plyyics, PEOPLE'S REPUBLIC OF CHIM

Prof. J.A.C. Cebre, Inetiut Suparior Teconico, POATUGAL

Dr. O. Petus, Al I CUzA Univ., Romania

Dr. J. do Vimien, Fusion Suctios, AEC, S. AFRICA

Prot. M.A. Hemoerg, Univ. of Nated, S. AFRiCA

Prot. D.E. Km, Pohuno ince. of Sad. Tech., SO. KOREA

Prot. C.I.E.MA.T, Fution Divicion Library, SPAN

Dr. L Simfio, Univ. of UMEA, SWEDEN

Librery, Royd inat of Tectinology, SWEDEN

Prot. H. Writemeon, Chamere Univ. of Tech., SWEDEN

Centre Phys. Des Ptaenas, Ecolo Polyech, SWITZERLAND

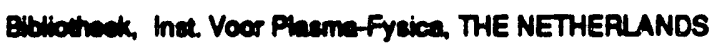

Aest Prot. Or. S. Codr, Midds East Tech. Univ., TUAKEY

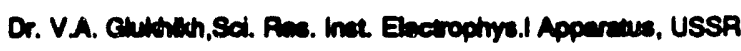

Dr. D.D. Ayutow, Stberien Brench of Academy of Soi., USSA

Dr. G.A. Elanew, I.V. Kurchatov Inat, USSA

Librerion, The Uler.SSA Acedemy of Scionces, USSA

Or. LM. Kowriatunyth, Inat, of Cenend Phyzica, USSA

Kentorectungeantegs GmbH, Zentrabibiotheck, W. GEPMANY

Bibliothate, Inst. For Pisematorschung, W. GERMANY

Prof. K. Schincier, Ruhr-Univeraitu Bochum, W. GERMANY

Dr. F. Weoner, (ASDEX), Max-Plenct-Inetieut, W. GERMANY

Librerion, Maxflunct-1natitu, W. GEPMANY

Prot. R.K Jenew, Inate of Phyaics, rucosLava 

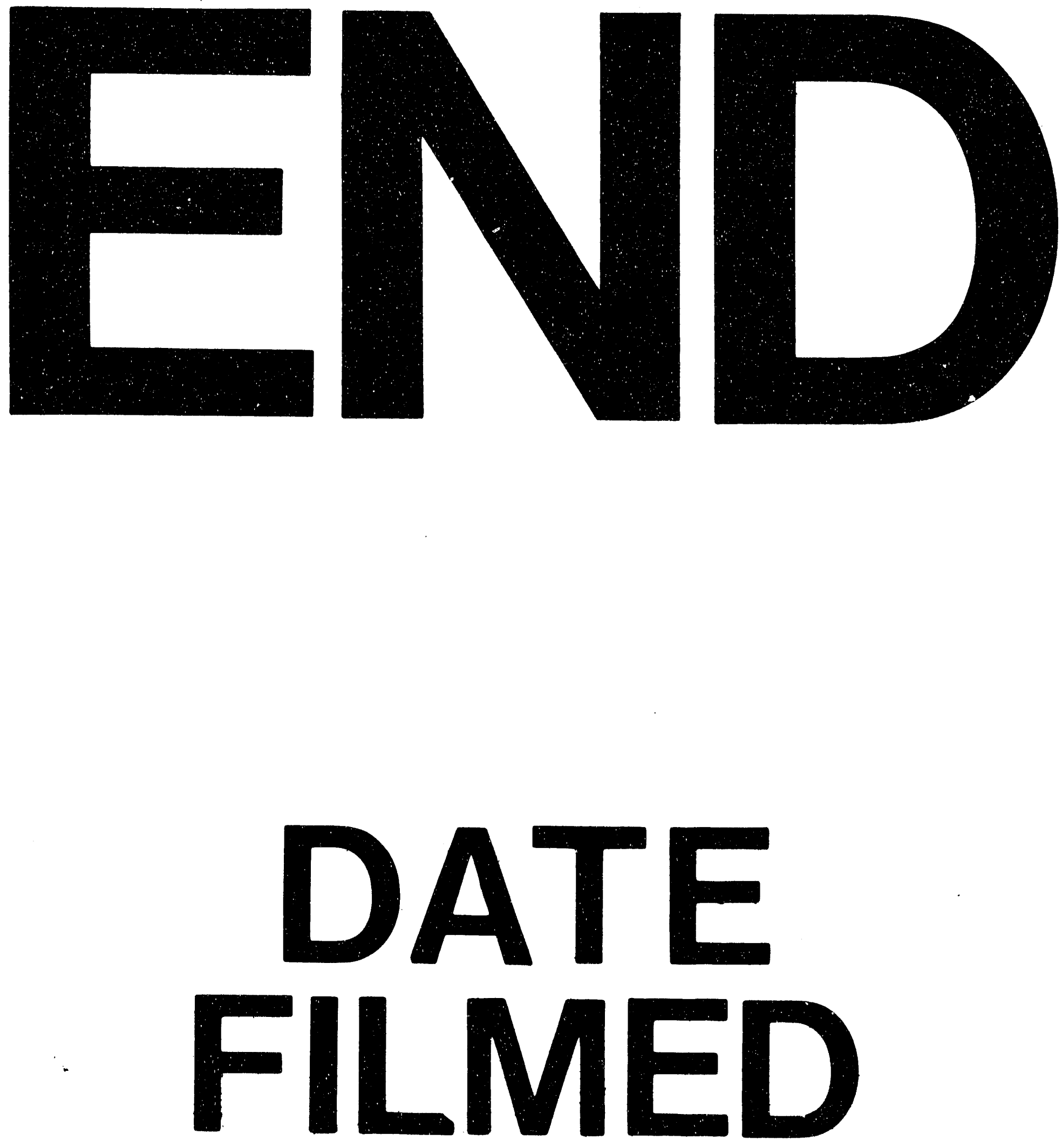

1

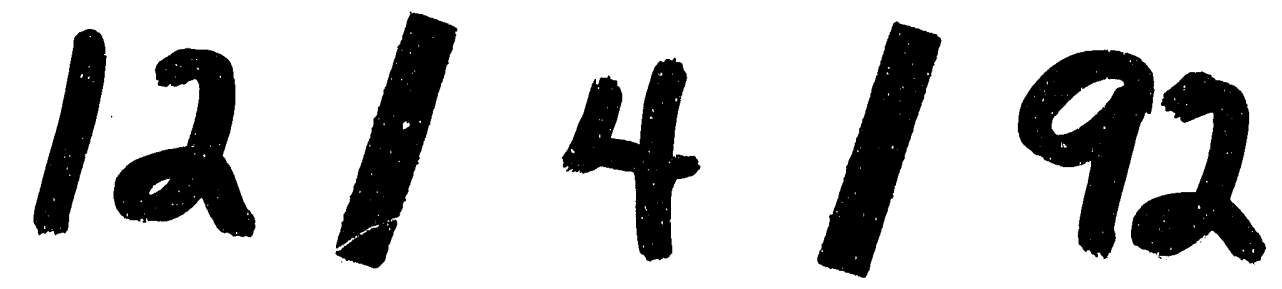


